\title{
Series Active Compensation of Current Harmonics Generated by High Power Rectifiers
}

\author{
D. Figueroa ${ }^{1}$, L. Morán ${ }^{1}$, G. Joos ${ }^{2}$ and J. Dixon ${ }^{3}$ \\ ${ }^{1}$ Department of Electrical Engineering \\ Universidad de Concepción \\ Casilla 160-C, Correo 3 - Concepción (Chile) \\ Phone/Fax number: +56 412204353 / +56 41224 6999, e-mail: dfigueroa@udec.cl, Imoran@udec.cl \\ ${ }^{2}$ Department of Electrical and Computer Engineering \\ McGill University \\ 3480 University Street, H3A2A7, Montreal, Québec (Canada) \\ Phone/Fax number: +1 514398 4455, e-mail: geza.joos@mcgill.ca \\ ${ }^{3}$ Department of Electrical Engineering \\ Pontificia Universidad Católica de Chile \\ Vicuña Mackenna 4860, Comuna Macul, Santiago (Chile) \\ Phone/Fax number: +56 23544198 / +56 2354 4076, e-mail: jdixon@ing.puc.cl
}

\begin{abstract}
This paper presents a series active filter to compensate current harmonics generated by high power rectifiers. The advantage of the proposed scheme is that is able to compensate current distortion by injecting a distorted voltage in only two lines, avoiding resonances and reducing compensator's rated capacity. The paper presents the series active filter in terms of principles of operation, design procedure, and compensation performance. Simulated results applied to an electro-winning rectifier demonstrate the viability of the proposed scheme. The proposed design procedure and compensation performance are demonstrated experimentally on a $10 \mathrm{kVA}$ laboratory prototype.
\end{abstract}

\section{Key words}

Active power filter, power quality, harmonic components, high power rectifiers.

\section{Introduction}

Different compensation techniques based in active and passive filters to eliminate current harmonics and to compensate reactive power have been presented and published [1,2,3]. Shunt, series and hybrid active filter topologies have been discussed and demonstrated to be an effective solution for non-linear load compensation. Although active filters are a good alternative for harmonic compensation, their applications in high power medium voltage are still limited due to power semiconductor ratings, higher cost and reduced reliability. So far, with traditional series active compensation it has not been possible to compensate current harmonics unless they are used with passive filters connected in parallel [4].

To reduce the effects of non-linear loads the conventional solution has been the utilization of second-order passive filters, since they can reduce current harmonics and improve the load's power factor. Nevertheless, practical implementation brings along several well known disadvantages, such as:

- Influence of the utility impedance in the filtering performance.

- Since the harmonic current and the fundamental frequency current flow through the filter, the rating of power components is high.

- If the harmonic content in the ac line voltage increases, the filter is overloaded.

- The risk of resonances between the filter and the utility impedances can amplify current harmonics to a dangerous level.

- Inrush currents are high and can activate overcurrent protections.

In order to overcome these problems, active power filters have been proposed and analyzed in the technical literature [1]-[4]. The classical shunt active power filter operates as a controlled current source while the series active approach acts as controlled voltage source. For these reasons, shunt active power filters are more suitable to compensate current harmonics and load reactive power, while the series approach compensates for voltage distortion, unbalances, and regulation. The principal 
disadvantages of active compensation techniques both shunt and series are the followings:

- Higher cost.

- More difficult and costly to implement on a large scale and at higher powers.

- For medium voltage application, both the inverter topology and its control scheme present a high degree of complexity.

The other well known topology is the hybrid filter [7], which employs a combination of an active and a passive filter, and is a good alternative for medium voltage applications; however, the compensation effectiveness depends on the passive filter tuned frequency.

This paper presents a current harmonic compensation technique based on two series active power filter, as shown in Fig. 1.

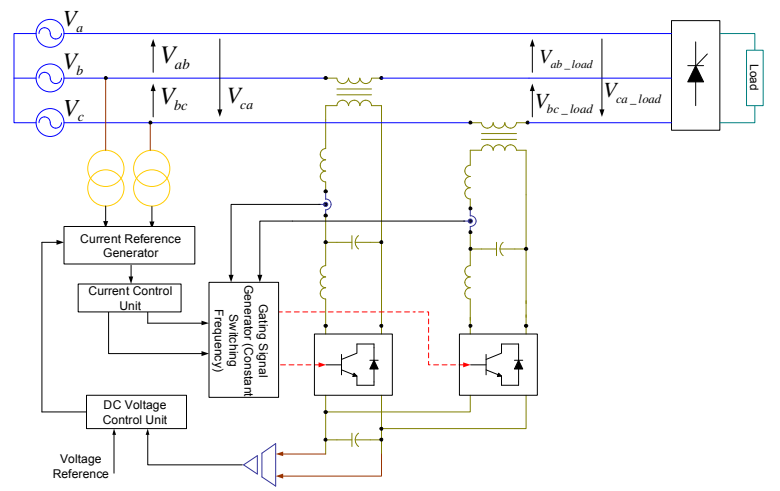

Fig. 1. Power circuit topology of the proposed series active filter including the control scheme block diagram.

The principal advantage of the proposed filter scheme is that requires only two single-phase PWM voltage-source inverters that share the same dc link capacitor, and are connected in series with the power distribution system through coupling transformers. Assuming that the load is not grounded, only two inverters can be used to compensate a three-phase load.

In order to generate sinusoidal ac system currents, the voltage at the load terminals must be distorted. It is important to note, that by changing the voltage waveform, especially for rectifiers type of loads, the rectifier operation and performance is not affected. Other operating characteristics include the following:

- Simple control scheme; only one sinusoidal signal is required as a control reference.

- The current compensation is done in time domain, resulting in a fast dynamic response.

- Load power factor can be corrected by forcing the load voltage to be in phase with the line current.

- The power circuit topology reduces the filter components part count, increasing reliability and reducing the total cost.

The analysis presented in this paper demonstrates the feasibility of the proposed compensation technique and its advantages in the compensation of large power rectifiers connected to a dedicated power distribution bus. The paper describes the principles of operation, control circuit design and implementation. Simulated steady state and transient results for the compensation of a 10 MVA phase controlled rectifier used in an electro-winning application are shown. In addition, a 10 $\mathrm{kVA}$ experimental prototype was implemented on a DSP digital control, and used to compensate a six pulse thyristor phasecontrolled rectifier. Simulated and experimental waveforms confirm the feasibility, verify the design procedure and analysis presented in this paper.

\section{Principle of Operation}

Current harmonics are compensated by injecting in series the same voltage harmonics as appear at the rectifier terminals, but phase-shifted in $180^{\circ}$, as shown in Fig. 2 .
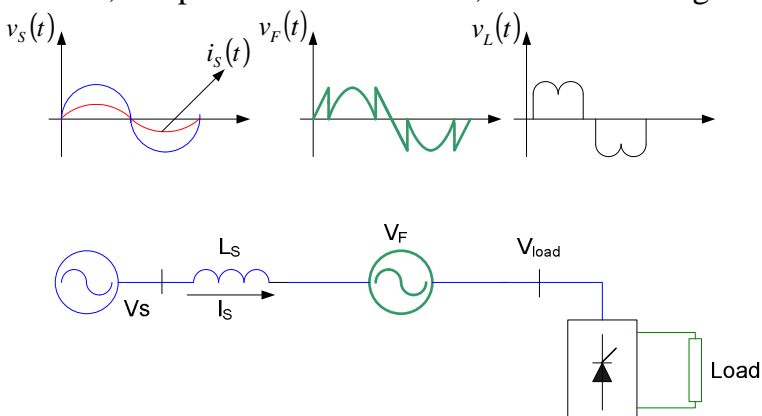

Fig. 2. Single-phase equivalent circuit and associated voltage and current waveforms of the proposed series active filter connected to a six pulse thyristor controlled rectifier $\left(\alpha=0^{\circ}\right)$.

In figure $2, v_{\mathrm{F}}(\mathrm{t})$ represents the voltage waveform injected by the series active power filter and $v_{\mathrm{L}}(\mathrm{t})$ the voltage at the load terminals. The voltage injected by the series active power filter is equal to the load voltage minus the fundamental component, phase-shifted by $180^{\circ}$. Figure 3 shows the single phase equivalent circuit for harmonic components and illustrates that current harmonic compensation is achieved if $\mathrm{V}_{\mathrm{F}-\mathrm{k}}$ is equal to $\mathrm{V}_{\mathrm{Load}-\mathrm{k}}$. If these two voltages are equal, they cancel each other, forcing $\mathrm{I}_{k}$ to be equal to zero. Current harmonic compensation is effective if the rectifier behaves as voltage source (with a capacitor connected in the dc bus). In case a reactor is connected to the rectifier dc bus, it behaves as a current source and the compensation effectiveness remains the same, but the rectifier $\mathrm{dc}$ voltage presents a larger distortion factor.

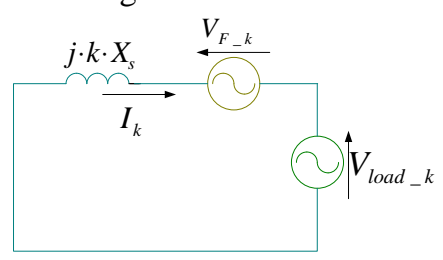

Fig. 3. Single-phase equivalent circuit of the series active filter for harmonic component $\left(\mathrm{X}_{\mathrm{S}}\right.$ system equivalent impedance, $\mathrm{V}_{\mathrm{F} \_\mathrm{k}}$ series active filter voltage, $\mathrm{V}_{\text {load_k }}$ rectifier input voltage harmonic component, $k$ order of the harmonic).

\section{Compensation Performance}

The compensation performance of the proposed series active filter scheme depends on the load characteristics, and is better if the rectifier behaves as a voltage source. Static rectifiers behave as voltage-sources if they have a dc capacitor connected at the dc bus. In case they have an inductive load, rectifiers behave as current sources. In case of current sources types of loads, the proposed series 
active power filter scheme also compensates current harmonics, but the $\mathrm{dc}$ voltage is more distorted. Simulated results obtained for both cases are shown in figures 4 and 5 .

Figure 4 shows simulated current and voltage waveforms of a 12 pulse voltage-source rectifier using the proposed series active power filter. Figure 4-a shows the compensated rectifier ac input current waveform (THD $=$ $4.8 \%$ ) demonstrating the compensation effectiveness of the proposed method. Figure 4-b shows the rectifier dc voltage with a distortion factor equals to $4.5 \%$. The low distortion factor of the dc voltage indicates that the proposed filter scheme does not affect the rectifier operating condition.

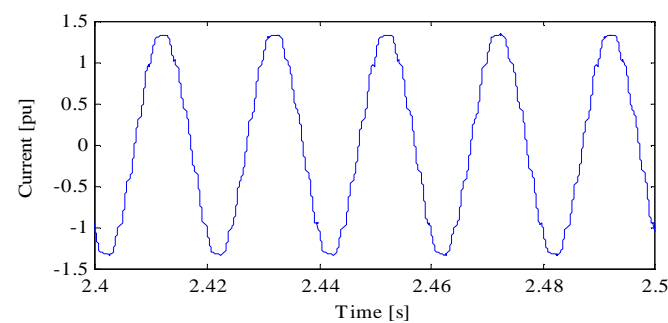

(a)

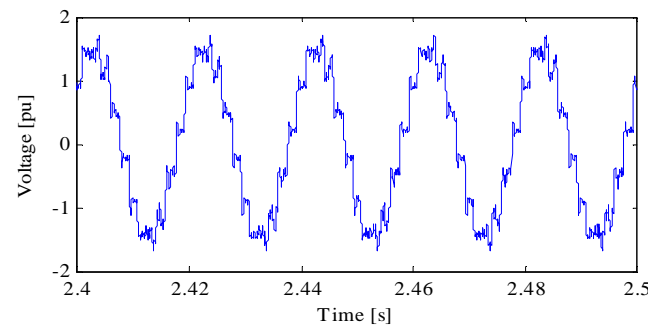

(b)

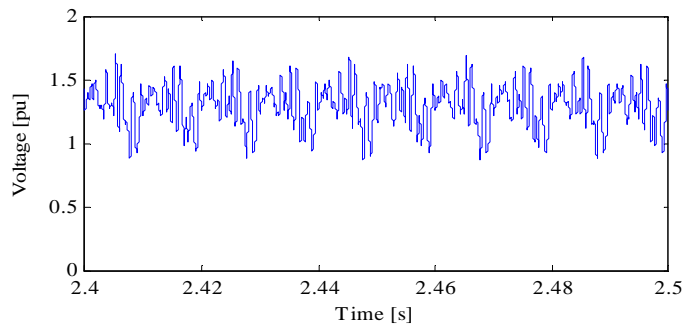

(c)
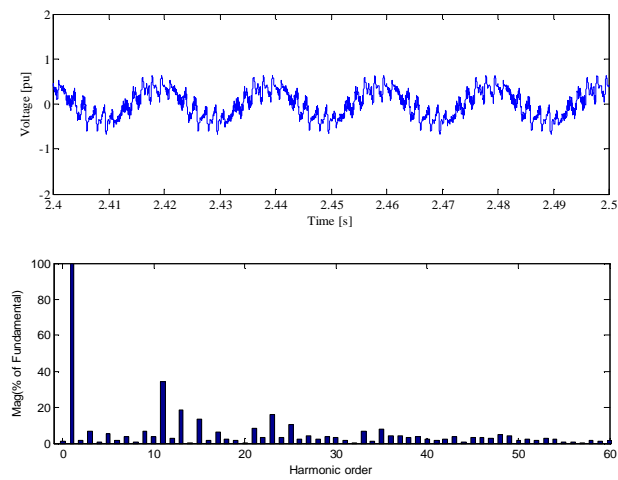

(d)

Fig. 4. Simulated waveforms of a 12 pulse voltage-source rectifier with the proposed series active power filter scheme (10 MVA, $13.8 \mathrm{kV})$. (a) Simulated ac input current waveform $(\mathrm{THD}=4.8 \%)$. (b) Simulated dc bus voltage (DF $=4.5 \%)$. (c) Voltage injected by the series active power filter and associated frequency spectrum $($ THD $=16.7 \%)$. (d) Simulated line to line voltage at the rectifier terminals.

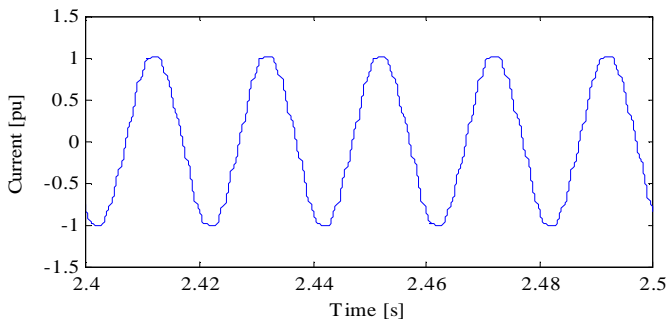

(a)

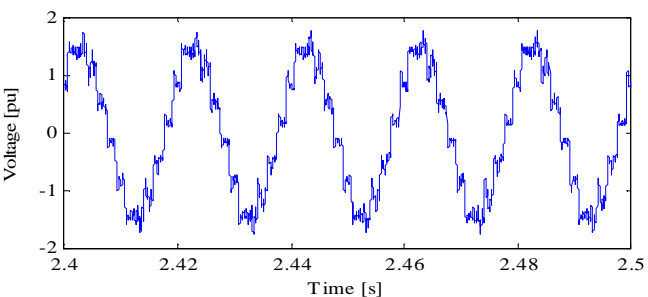

(b)

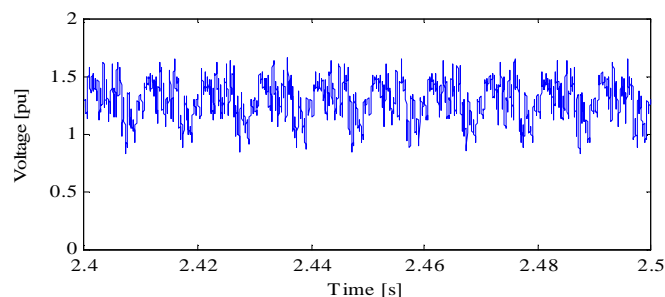

(c)
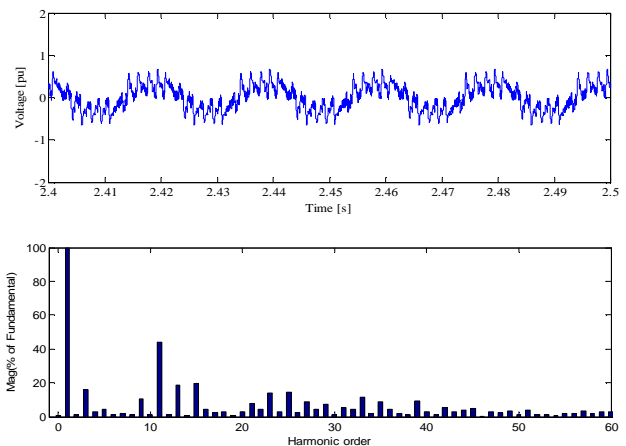

(d)

Fig. 5. Simulated waveforms of a 12 pulse current-source rectifier with the proposed series active power filter scheme (10 MVA, $13.8 \mathrm{kV})$. (a) Simulated ac input current waveform (THD $=4,5 \%)$. (b) Simulated dc bus voltage (DF = 5,3\%). (c) Voltage injected by the series active power filter and associated frequency spectrum. (THD $=18,2 \%)(\mathrm{d})$ Simulated line to line voltage at the rectifier terminals.

Simulated results illustrate the compensation performance of the proposed filter scheme. Power factor can also be compensated by forcing the ac source voltage to be in phase with the respective line current. Since the proposed series scheme injects voltages in only two phases the reactive power compensation range is limited. In case of thyristor-controlled rectifiers, power factor can be kept equal to unity down to a phase-shift angle of $30^{\circ}$.

\section{Filter Design Procedure}

The series active power filter is composed of two single phase full bridge inverters, a common dc capacitor, an LCL output filter and two coupling transformers. The controller has two control loops, one to keep the dc voltage constant, and the second one to generate the 
inverter output voltage required to compensate line current harmonics.

\section{A. DC Capacitor.}

The dc capacitor value is obtained using (1). With this value, the capacitor is able to store enough energy to supply the instantaneous power required by the ac system during half a cycle without resulting in dc voltage variations of more than $5 \%$.

$$
C_{D C} \geq \frac{V_{s m} \cdot I_{L m} \cdot T / 2}{\left(V_{D C r e f}^{2}-V_{D C}^{2}\right)}
$$

$\mathrm{V}_{\mathrm{sm}}$ is the ac system phase to neutral peak value, $\mathrm{I}_{\mathrm{Lm}}$ is the $r m s$ load current, $T$ is the ac system period, $\mathrm{V}_{\mathrm{DCref}}$ is the $\mathrm{dc}$ voltage reference value and $\mathrm{V}_{\mathrm{DC}}$ is the minimum voltage allow in the dc bus.

\section{B. LCL output filter.}

The output filter eliminates the ripple voltage generated by the single phase PWM full bridge inverter. Its design is based on the maximum high frequency voltage harmonic amplitude allowed at the coupling transformer terminals. The filter must not attenuate the low frequency voltage harmonics required to eliminate the load current harmonic. $\mathrm{C}_{\mathrm{F}}$ is equal to $5 \%$, with respect to the base impedance, and can be calculated using (2).

$$
\begin{aligned}
C_{F} & =x \cdot \frac{S_{n}}{\omega \cdot E_{n}^{2}}=x \cdot C_{b} \\
C_{F} & \leq 0.05 \cdot \frac{S_{n}}{\omega \cdot E_{n}^{2}}=0.05 \cdot \frac{1}{\omega \cdot Z_{b}}
\end{aligned}
$$

Where $S_{n}$ and $E_{n}$ are the rated load apparent power and rated phase to neutral voltage.

Filter inductances $\mathrm{L}_{\mathrm{F}}$ and $\mathrm{L}$ attenuate current harmonics generated by the PWM inverter. Total filter inductance is obtained from (3).

$$
L_{T} \approx \frac{V_{D C}}{8 \cdot i_{r p_{-} \max } \cdot f_{S W}}=L_{F}+L
$$

The ratio between $\mathrm{L}_{\mathrm{F}}$ and $\mathrm{L}$ is defined by a constant " $\mathrm{r}$ ", and depends on the high frequency current harmonic that flows through the coupling transformer (4) - [8], [9].

$$
\frac{i_{O}\left(\omega_{S W}\right)}{i_{i n v}\left(\omega_{S W}\right)}=\frac{1}{\left|1+r \cdot\left(1-\left(L \cdot C_{b} \cdot \omega_{S W}^{2}\right) \cdot x\right)\right|}
$$

Table I shows the parameter values of the proposed LCL filter in pu and absolute values, for a 12 pulse rectifier rated at $10 \mathrm{MVA}$ and $13.8 \mathrm{kV}$.

The rated $\mathrm{kVA}$ of the series active filter is $20 \%$ of the load rated power. In this case, the series active power filter compensates for current harmonics and reactive power, up to a 0.87 load power factor.
Table I. - LCL Passive Filter Values.

\begin{tabular}{|l|c|c|}
\cline { 2 - 3 } \multicolumn{1}{c|}{} & Real Value & p.u. value \\
\hline $\mathrm{L}$ & $1,4 \mathrm{mH}$ & 0,023 \\
\hline $\mathrm{L}_{\mathrm{F}}$ & $1,4 \mathrm{mH}$ & 0,023 \\
\hline $\mathrm{C}_{\mathrm{F}}$ & $8 \mathrm{uF}$ & 20,893 \\
\hline $\mathrm{C}_{\mathrm{DC}}$ & $1000 \mathrm{uF}$ & 0,167 \\
\hline
\end{tabular}

The design procedure for the current and voltage loops is based on the respective time response requirements. The transient response of the active power filter is determined by the current control loop (internal loop). It must be fast enough to force the current to follow the reference waveform as closely as possible [10]. The response time of the dc voltage control loop does not need to be fast, due to the slow dynamics of the electrolytic capacitor, and is selected to be at least 10 times slower than that of the current control loop [10]. In this way, both control loops can be decoupled and be designed as two independent systems.

\section{Experimental Results}

A $10 \mathrm{kVA}$ laboratory prototype using IGBT switches was implemented and tested for compensating a six pulse phase-controlled rectifier. Each inverter was operated at a $3.5 \mathrm{kHz}$ switching frequency. The control strategy was implemented in a DSP TMS320C24x. Steady state and transient results are shown in Figs. 6, 7 and 8. Steady state results demosntrate the feasibility of the proposed compensation scheme. Figure 8 shows the current and voltage waveforms of the six pulse rectifier without compensation. Figure 8 shows steady state waveforms with the compensation scheme. The THD of the system current is reduced from $27.4 \%$ to $6.9 \%$ by applying the compensation method.

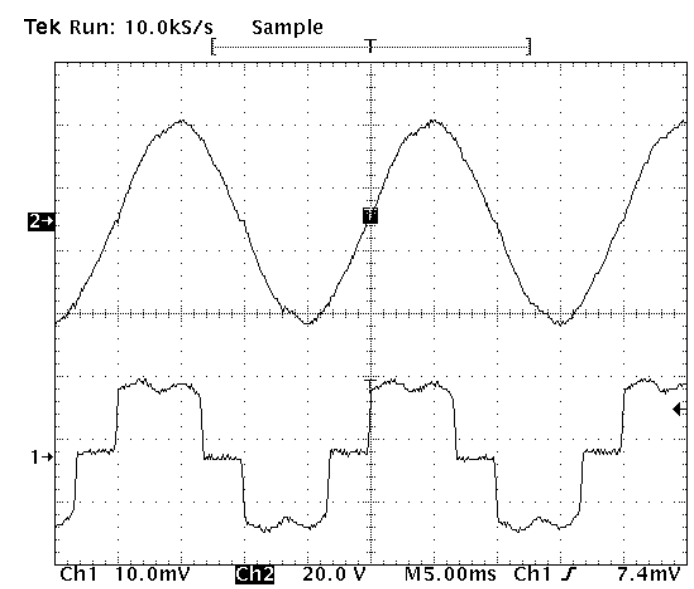

Fig. 6. Rectifier input current and voltage experimental waveforms without compensation. (a) Rectifier input line to neutral voltage $V_{\text {an }}(200 \mathrm{~V} /$ div $)$. (b) Rectifier input current $I_{b}(5$ A/div). 


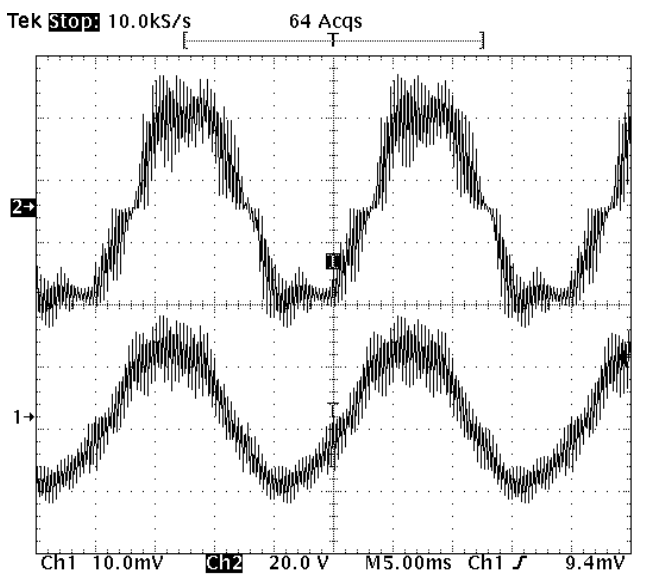

Fig. 7. Steady state rectifier input current and input voltage experimental waveforms with compensation. (a) Rectifier input line to line voltage $\mathrm{V}_{\mathrm{ab}}(200 \mathrm{~V} / \mathrm{div})$. (b) Rectifier input current $\mathrm{I}_{\mathrm{b}}(5 \mathrm{~A} / \mathrm{div})$.

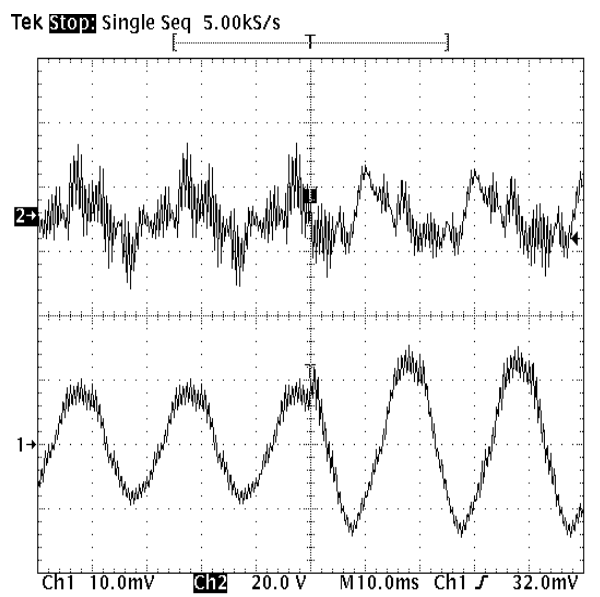

Fig. 8. Experimental transient results. Rectifier input line to line voltage and input line waveforms with compensation. (a) Rectifier input line to line voltage $\mathrm{V}_{\mathrm{ab}}(200 \mathrm{~V} / \mathrm{div})$. (b) Rectifier input current $\mathrm{I}_{\mathrm{b}}(5 \mathrm{~A} / \mathrm{div})$.

\section{Conclusions}

A series active compensation scheme to eliminate current harmonics generated by high power static rectifiers was presented and analyzed. The proposed active compensation technique is based in a series active filter that employs two single-phase inverters with a simple control scheme. Experimental results obtained on a laboratory DSP based controlled prototype were presented, validating the simulated waveforms and confirming the feasibility of the proposed compensation technique.

\section{Acknowledgements}

The authors would like to acknowledge the financial support obtained from "FONDECYT" through the 1080237 project.

\section{References}

[1] Hideaki Fujita, Takahiro Yamasaki, and Hirofumi Akagi, "A Hybrid Active Filter for Damping of Harmonic Resonance in Industrial Power Systems", IEEE Trans. on Power Electronics, vol. 15, No. 2, March 2000.

[2] Rubén Inzunza and Hirofumi Akagi, "A 6.6-kV Transformerless Shunt Hybrid Active Filter for Installation on a Power Distribution System", IEEE Trans. on Power Electronics, vol. 20, No. 4, July 2005.

[3] Zhiguo Pan, Fang Z. Peng, and Suilin Wang, "Power Factor Correction Using a Series Active Filter", IEEE Trans. on Power Electronic, vol. 20, No. 1, January 2005.

[4] Abraham D. le Roux, Hendrik du T. Mouton, and Hirofumi Akagi, "Digital Control of an Integrated Series Active Filter and Diode Rectifier with Voltage regulation", IEEE Trans. on Ind. Appl., vol. 39, N6, Nov./Dec. 2003.

[5] Luis A. Morán, Juan W. Dixon, Rogel R. Wallace, "A Three-Phase Active Power Filter Operating with Fixed Switching Frequency for Reactive Power and Current Harmonic Compensation”, IEEE Trans. on Ind. Electron, vol. 42, N4, August 1995.

[6] Vijay B. Bhavaraju and Prasad N. Enjeti, "An Active line Conditioner to Balance Voltages in a Three-Phase System", IEEE Trans. on Ind. Appl., vol. 32, N², March./April 1996.

[7] Sangsun Kim and Prasad N. Enjeti, "A New Hybrid Active Power Filter (APF) Topology", IEEE Transactions on Power Electronics, vol. 17, no. 1, January 2002.

[8] M. Liserre, F. Blaabjerg and S. Hansen, "Design and Control of an LCL-filter based Three phase Active Rectifier" Industry Applications Conference, 2001. Thirty-Sixth IAS Annual Meeting. Conference Record of the 2001 IEEE. Vol. 1, pp 299-307. September/October 2001.

[9] Y. Lang, D. Xu and S. Hongfei Ma, "A Novel Design of LCL Type Utility Interface for ThreePhase Voltage Source Rectifier" Power Electronics Specialists Conference, 2005. PESC '05. IEEE 36th. pp 313-317. June 2005.

[10] D. Figueroa, L. Morán, P. Ruminot, J. Dixon, “A series Active Power Filter for Current Harmonic Compensation," in IEEE PESC Conf. Record, June 2008, Greece. 